\title{
Assessment of efficacy of Anti-IgE (Omalizumab) therapy in patients with severe allergic asthma in a tertiary care hospital of Eastern India
}

\author{
Ghosh S. ${ }^{1}$, Gayen P. ${ }^{2}$, Mandal A. ${ }^{3 *}$, Bandyopadhyay R. ${ }^{4}$ \\ DOI: https://doi.org/10.17511/ijmrr.2019.i03.10
}

\footnotetext{
${ }^{1}$ Saswata Ghosh, Assistant Professor, Department of Chest Medicine, Malda Medical College and Hospital, Malda, West Bengal, India.

2 Prosenjit Gayen, Assistant Professor, Department of Pathology, Malda Medical College and Hospital, Malda, West Bengal, India.

3* Animesh Mandal, Assistant Professor, Department of Chest Medicine, Malda Medical College and Hospital, Malda, West Bengal, India.

${ }^{4}$ Ramtanu Bandyopadhyay, Professor, Department of General Medicine, Malda Medical College and Hospital, Malda, West Bengal, India.
}

Introduction: Immunoglobulin E dependent mechanisms play an important role in the development of airway inflammation in allergic asthma. Atopic patients with severe asthma frequently have poorly controlled disease. Many have poor asthma control despite intensive treatment. Severe allergic asthma patients frequently treated with oral corticosteroids and therefore may develop serious sideeffects. Anti-IgE antibody had been used in severe persistent allergic asthma in Western countries. However, its long-term efficacy in patients in India has not been reported. Objective: To assess the efficacy of anti IgE therapy in patients with severe allergic asthma. Method: 30 (16 male and 14 female) patients, with mean age of 49 having severe persistent allergic asthma, with recurrent exacerbations and on oral/IV steroids, received Omalizumab 150mg/300mg/450 mg for 1 year. Total dose of oral Steroids, use of rescue medications, changes in lung function (FEV1) were recorded at the baseline, 16 weeks \& at end of the treatment (52 weeks) and then analyzed. Results: Significant reduction observed in total oral steroid use at 16 week \& at 52 weeks. $-10.5 \mathrm{mg}$ $(p<0.003) \& 22.5 \mathrm{mg}$ respectively. Use of rescue medications decreased by -7.90 puffs $(p-<0.001)$ at 16 weeks and by -13.67 puffs $(13.67$ ( $p-<0.001)$ at 52 weeks. Improvements in lung Function (FEV1) observed with a tune of $700 \mathrm{ml}$. from Baseline after 52 weeks therapy. Conclusion: Use of anti-IgE antibody for 1 year is well tolerated and led to an overall significant improvement in patients with severe persistent allergic asthma.

Keywords: Severe allergic asthma, Anti IgE therapy, Omalizumab

Corresponding Author

Animesh Mandal, Assistant Professor, Department of Chest Medicine, Malda Medical College and Hospital, Malda, West Bengal, India.

Email: drsaswata1969@gmail.com
How to Cite this Article

To Browse

Ghosh S, Gayen P, Mandal A, Bandyopadhyay R. Assessment of efficacy of Anti-IgE (Omalizumab) therapy in patients with severe allergic asthma in a tertiary care hospital of Eastern India. Int J Med Res Rev. 2019;7(3):206-211.

Available From

https://ijmrr.medresearch.in/index.php/ijmrr/article/

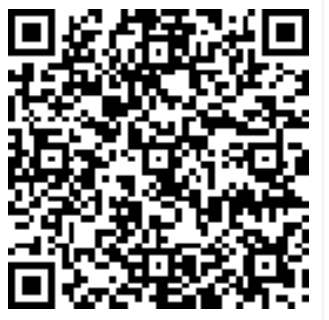
view/1060

Manuscript Received 2019-05-06

Conflict of Interest No
Review Round 1 2019-05-26

Funding $\mathrm{Nil}$

Review Round 2
2019-06-04
Ethical Approval
Yes

Review Round 3

Accepted 2019-06-08

Plagiarism $\mathbf{X}$-checker $8 \%$

(c) 2019 by Saswata Ghosh, Prosenjit Gayen, Animesh Mandal, Ramtanu Bandyopadhyay and Published by Siddharth Health Research and Social Welfare Society. This is an Open Access article licensed under a Creative Commons Attribution 4.0 International License https://creativecommons.org/licenses/by/4.0/ unported [CC BY 4.0]. 


\section{Introduction}

Asthma remains a major public health problem and a significant proportion of patients have severe, persistent disease that is refractory to continuous treatment, even with a combination of high-dose inhaled corticosteroids and long-acting b2-agonists. Maintenance oral corticosteroids (OCS) are frequently administered to achieve control in those patients [1]. However, regular OCS use is associated with significant systemic side effects including cataracts, high blood sugar among non-diabetics, osteoporosis, acne, weight gain, sleep and mood disturbances [2].

Omalizumab is a recombinant, DNA-derived, humanized monoclonal antibody that selectively binds to human IgE. This prevents the interaction of IgE to the high-affinity receptors on basophils and mast cells, thus interrupting the inflammatory cascade involved in the pathogenesis of allergic asthma. Several studies have demonstrated the therapeutic efficacy and safety of omalizumab in asthmatic patients and have found a reduced annual rate of clinically significant asthma exacerbations, systemic requirements of corticosteroids, emergency department (ED) visits, and overall symptoms $[1,3,4,5]$.

This therapy has been incorporated into the current guidelines for the treatment of asthma. Current GINA guidelines recommend use of omalizumab as a step 5 treatment, in patients who remain symptomatic despite optimum treatment [6]. The study was undertaken to investigate the clinical effects of omalizumab (Anti IgE) therapy in a population of Indian patients with severe, persistent, allergic asthma.

According to American Academy of Allergy, Asthma and Immunology, Allergic asthma is the most common form of asthma. Many of the symptoms of allergic and non-allergic asthma are the same. However, allergic asthma is triggered by inhaling allergens. An allergen is a typically harmless substance such as dust mites, pet dander, pollen or mold. If you are allergic to a substance, this allergen triggers a response starting in the immune system.

Through a complex reaction, these allergens then cause the passages in the airways of the lungs to become inflamed and swollen. This results in coughing, wheezing and other asthma symptoms.
The definition of severe asthma (according to ERS/ATS 2014) is that group of patients who needs treatment with high-dose ICS + at least one additional controller (LABA, montelukast, or the ophylline) or oral corticosteroids $>6$ months/year.

Objective: To assess the efficacy of anti IgE therapy in patients with severe allergic asthma.

\section{Methods}

01. a) Study Type: Single centre, 52-week, observational study conducted at Medical College and Hospital, Malda in Eastern India. Place of study: OPD, Department of Chest Medicine, Malda Medical College \& Hospital, Malda.

02. b) Sample Size: Total 30 patients with severe allergic asthma were enrolled.

03. c) Sampling Technique: Consecutive non probability technique used.

04. d) Inclusion Criteria: Clinical diagnosis of severe asthma, positive allergy test results for at least 1 perennial aeroallergen, IgE level 30 to $1500 \mathrm{IU} / \mathrm{ml}$, regular/occasional requirement of systemic steroid treatment (IV or oral), and frequent exacerbations requiring emergency visit/ hospitalization.

05. e) Exclusion Criteria: 1) Mild to moderate asthma 2) Severe allergic asthma but with comorbidities 3) Patients unwilling to join the study.

06. f) Study Procedure: Study commenced after obtaining permission from Institutional Ethical Committee and written informed consent from patients. Data were obtained from patients diagnosed with severe allergic asthma, and received omalizumab. Omalizumab was administered according to a dosing table nomogram incorporating the patients' bodyweight and baseline IgE levels.

Data Analysis: Data on the following parameters were collected at Baseline (prior to commencing omalizumab therapy), 16 weeks and 52 weeks after omalizumab initiation:

- OCS (Oral Corticosteroid)dose

- ACT (Asthma Control Test) score

- Use of rescue medication, and

- Lung function (FEV1) 
Change in ICS dose, LABA dose, and status of asthma control (mild, moderate, or severe) were also recorded.

Summary statistics describing change from baseline in OCS dose, ACT score, rescue medication use and change in FEV1 were calculated for all patients receiving omalizumab.

\section{Results}

A total of 30 patients (53.3\% male, $46.7 \%$ female) who were receiving omalizumab were included in this study.

Table 1: Demographic profile of patients.

\begin{tabular}{|l|l|}
\hline \multicolumn{1}{|c|}{ Variable } & \multicolumn{1}{|c|}{$\begin{array}{c}\text { Patients } \\
(\mathrm{n}=\mathbf{3 0})\end{array}$} \\
\hline Mean age, years & 53.3 \\
\hline Female, $\mathrm{n}(\%)$ & $14(46.7 \%)$ \\
\hline Mean duration of allergic asthma, years & 28.6 years \\
\hline $\begin{array}{l}\text { Positive skin-prick test/RAST for perennial aeroallergens, } \\
(\%)\end{array}$ & $95.6 \%$ \\
\hline History of seasonal allergy, (\%) & $67.3 \%$ \\
\hline Smoking history, $(\%)$ & \\
\hline
\end{tabular}

\begin{tabular}{|l|l|}
\hline Never smoked & $78.6 \%$ \\
\hline Ex-smoker & $15.8 \%$ \\
\hline Current smoker & $5.6 \%$ \\
\hline Asthma control/severity (investigator assessment), (\%) \\
\hline Controlled & 0 \\
\hline Partly controlled/Moderate & $30 \%$ (9 patients) \\
\hline Uncontrolled/severe & $70 \%$ (21 patients) \\
\hline
\end{tabular}

Classified by severity, $70 \%$ of the patients have severe asthma, and $30 \%$ had moderate (partially controlled) asthma. No patients with mild (wellcontrolled) asthma were included in the study. The key baseline characteristics are listed in the table above:

OCS (Oral Corticosteroid) dosing: The mean total daily OCS dose reduction at 16 week \& at 52 weeks from Baseline was $10.5 \mathrm{mg}(p<0.003) \&$ $22.5 \mathrm{mg}$, respectively. The proportion of patients receiving OCS was lower at Week 16 (40\%) and week $52(23.3 \%)$ than at baseline (76.6\%). The experience registry - the 2 year, multi-center, noninterventional study of 916 patients also demonstrated that add-on therapy with Omalizumab was associated with a reduction(32.9 \% in week 52 ) in the use of OCS and rescue therapy.

Table 2: ACT (Asthma Control Test) score.

\begin{tabular}{|c|c|c|c|c|c|}
\hline & 1 points & 2 points & 3 points & 4 points & 5 points \\
\hline \multirow{2}{*}{$\begin{array}{l}\text { Everyday } \\
\text { restriction }\end{array}$} & \multicolumn{5}{|c|}{ In the past 4 weeks how much of the time did your asthma keep you from getting as much done at work. school or at home? } \\
\hline & All of the time & Most of the time & Some of the time & A little of the time & None of the time \\
\hline \multirow{2}{*}{$\begin{array}{l}\text { Daytime } \\
\text { complaints }\end{array}$} & \multicolumn{5}{|c|}{ During the past 4 weeks. how often have you had shortness of breath? } \\
\hline & More than_once a day & Once a day & 3 to 6 times_a week & Once or twice_a week & Not at all \\
\hline \multirow[t]{2}{*}{$\begin{array}{l}\text { Nighttime } \\
\text { complaints }\end{array}$} & \multicolumn{5}{|c|}{$\begin{array}{l}\text { During the past } 4 \text { weeks. how often did your asthma symptoms (wheezing. coughing. shortness of breath. chest tightness or pain) wake you } \\
\text { up at night or earlier than usual in the morning? }\end{array}$} \\
\hline & 4 or more nights a week & 2 or 3 nights a week & Once a week & Once or twice & Not at all \\
\hline \multirow{2}{*}{ Rescue inhaler } & \multicolumn{5}{|c|}{ During the past 4 weeks. how often have you used your rescue inhaler or nebulizer medication (such as albuterol)? } \\
\hline & 3 or more times per day & 1 or 2 times per day & 2 or 3 times per week & Once a week or less & Not at all \\
\hline \multirow{2}{*}{ Subjective } & \multicolumn{5}{|c|}{ How would you rate your asthma control during the past 4 weeks? } \\
\hline & Not controlled at all & Poorly controlled & Somewhat controlled & Well controlled & Completely controlled \\
\hline
\end{tabular}

In the ACT (4) five questions must be answered and between 1 and 5 points are assigned per answer. There is thus a maximum score of 25 . The definition established by the European Respiratory Society and the American Thoracic Society in 2014 defines severe asthma as a score under 20 during highdose ICS (inhaled corticosteroid) therapy with an additional controller or during oral corticosteroid
Therapy for more than 6 months per year. Improvements were seen ACT scores at week 16 (score 17.1 vs. 11.3 at baseline) and week 52 (20.8 vs 11.3 at baseline). The retrospective APEX (Asthma Patient Experience on Xolair) study in clinical practice in the UK $(n=136)$ shows improvement in ACT Score at week 52 (20 vs 11 at baseline). 
In experience registry there was improvements in ACT Score at week 52 (19.1 vs 13 at baseline).

Rescue medication use: Use of rescue medications decreased by 7.90 puffs $(p<0.001)$ at 16 weeks and by 13.67 puffs $(p<0.001$ ) at 52 weeks from baseline. In experience registry there was improvements in rescue medication use (54.1 vs $87 \%$ patients at baseline). In the study by Holgate et al. the use of rescue medicine was reduced from baseline significantly more with omalizumab than placebo, and differences were significant from week 8 to study end ( $p \leq 0.05$ to $<0.001)$.

Lung function: Lung function was improved significantly compared to baseline (change in FEV 1 $=700 \mathrm{ml}$ ) at 52 weeks.

In INNOVATE Study the FEV1 ( $\%$ predicted) was significantly improved with Omalizumab as compared to placebo at week 28 with a difference of $2.8 \%$ predicted in favour of Omalizumab. Improvements in FEV1 were $190 \mathrm{ml}$ and $96 \mathrm{ml}$ in the omalizumab and placebo groups, respectively.

Table 3: Other parameters: The change in ICS dose and LABA dose are shown in below table:

\begin{tabular}{|l|l|l|}
\hline Parameter & \multicolumn{1}{|c|}{$\begin{array}{c}\text { Mean change from } \\
\text { Baseline at } 16 \text { weeks }\end{array}$} & $\begin{array}{c}\text { Mean change from Baseline } \\
\text { at } 52 \text { weeks }\end{array}$ \\
\hline ICS dose & $-287.50 \mathrm{mg}(\mathrm{p}<.001)$ & $-458.33 \mathrm{mg}(\mathrm{p}<.05)$ \\
\hline LABA dose & $-26.25(\mathrm{p}<.001)$ & $-58.33(\mathrm{p}<.001)$ \\
\hline
\end{tabular}

\section{Discussion}

A Cochrane review published in 2006 by Walker $S$, Monteil M, Phelan K, Lasserson T, Walters E of 14 randomized controlled trials in 3143 children and adults with mild to severe allergic asthma found that treatment with omalizumab reduced asthma exacerbations (OR $0.52,95 \% \mathrm{CI}, 0.41$ to 0.65 ) and increased the proportion of patients who were able to reduce or withdraw inhaled corticosteroids [8]. In our study there were also reduced asthma exacerbations as shown in ACT scores - week 16 (score 17.1 vs. 11.3 at baseline) and week 52 (20.8 vs 11.3 at baseline).

A systematic review published in 2011 by Rodrigo GJ, Neffen H, Castro-Rodriguez J. of 8 randomized controlled trials in 3,429 children and adults with moderate to severe allergic asthma taking inhaled corticosteroids, including two trials published after $2006[10,11]$ concluded that omalizumab treatment resulted in a higher proportion of subjects steppingdown and stopping inhaled corticosteroids
(Relative risk $[R R]=1.80 ; 95 \% C I, 1.42-2.28)$ and reduced the risk of asthma exacerbations ( $R R=$ 0.57; 95\% CI, 0.48-0.66) [9]. Similarly, in our study use of rescue medications decreased by 7.90 puffs ( $p<0.001$ ) at 16 weeks and by 13.67 puffs ( $p$ $<0.001)$ at 52 weeks from baseline.

Data from the systematic review published in 2011suggested that the number needed to treat for benefit (NTTB) in reducing the rate of exacerbations was 10. A post-hoc analysis suggested that the beneficial effects of omalizumab were not dependent on the age, duration of treatment, or disease severity. A study included in the systematic review that provided evidence for the efficacy of omalizumab in children was a 52 week randomized placebo-controlled trial in 627 children aged 6 to $<12$ years with perennial allergen asthma and a history of exacerbations and poor symptom treatment with medium-dose or high-dose inhaled corticosteroids with or without other controller medications.

Omalizumab treatment reduced asthma exacerbations by $31 \%$ compared to placebo during the first 24-weeks of the study, when the inhaled corticosteroid dose remained stable, and by $43 \%$ over a period of 52 weeks, which included a 28week adjustable-corticosteroid phase. In this study the secondary outcomes including symptoms, reliever bronchodilator use and reduction in inhaled corticosteroid dose were not significantly improved by omalizumab treatment $[9,10]$.

Recent publications by Ohta $\mathrm{K}$, Miyamoto $\mathrm{T}$, Amagasaki T, Yamamoto $M$ and Hanania NA, Alpan O, Hamilos DL, Condemi JJ, Reyes-Rivera I, Zhu J, et al have provided important new information on the use of omalizumab as an add-on treatment to high dose inhaled corticosteroids and inhaled longacting $\beta 2$ agonist bronchodilators in severe allergic asthma and in children and young adults with allergic asthma $[11,12]$.

A randomized controlled trial in 850 patients who had inadequately controlled asthma despite treatment with high dose inhaled corticosteroids ( $\geq 500 \mathrm{mcg}$ of fluticasone inhaler twice daily or equivalent) and inhaled long-acting $\beta 2$ agonist bronchodilators, with or without other controllers assessed the benefits of the addition of omalizumab over a 48 week period [11]. At the end of the treatment period omalizumab produced a $25 \%$ relative reduction in the rate of asthma exacerbations. 
Our study also demonstrates clinical benefits obtained from the addition of omalizumab to patients with poorly controlled severe allergic asthma despite treatment with high dose inhaled corticosteroids and inhaled long-acting $\beta 2$ agonist bronchodilators, although the magnitude of benefit is relatively small.

Interestingly there was a large placebo effect observed in the control group, a finding which has been noted in previous studies with omalizumab. At baseline, seventeen percent of participants were receiving either chronic oral corticosteroids or an oral corticosteroid course at least 4 times per year, and in this sub-group there was no clinical benefit although it should be noted that the study was not powered to detect a treatment effect $[12,13]$.

Several observational studies have reported on 'real life' experience with omalizumab in treating patients with allergic asthma in France [15], Germany [16], Belgium [17], United Kingdom [18], Italy [19], South-Eastern Mediterranean centers [20], Israel [21], Spain [22] and other countries. Taken together, the results of these studies suggest that omalizumab is an effective treatment for patients with poorly controlled allergic asthma and that is comparable to our study. Our findings are in agreement with those of other studies of omalizumab in various parts of the world, a brief account of which is compared below [8-23]:

Summary and Conclusion: In this study, omalizumab was associated with a reduction in maintenance OCS use in patients with uncontrolled persistent allergic asthma. The mean daily requirement of OCS, as well as the number of patients on OCS - both have been reduced significantly with omalizumab treatment for 52 weeks.

The use of OCS is associated with serious long-term adverse effects such as hypothalamic-pituitaryadrenal axis suppression, impaired glucose tolerance and diabetes, osteoporosis, hypertension, and cataract formation. Therefore, a therapy that improve outcomes, have acceptable safety and tolerability profiles, while allowing reductions in OCS use is really helpful for the patients.

In addition of reduction in OCS use, patients enrolled in the study also experienced an significantly improved lung function and a significant reduction in daily rescue medication use. These two parameters are very closely related to patients' overall quality of life.
Although measurement of QoL was in the scope of this study, it is expected to improve significantly as implied from the other parameters [7].

The maintenance dose of ICS and LABA were also reduced significantly in this study, which suggested an improvement in asthma control. This is further demonstrated by the status of asthma severity analysis, which showed after 52 weeks, no patients were classified as 'severe' asthmatics.

So to conclude, it can be said that Omalizumab is a recombinant humanized monoclonal antibody that binds circulating IgE antibody.

It is approved in the US and Europe, as well as many other countries, for the treatment of adults and adolescents aged 12 years and above with moderate to severe persistent allergic asthma, whose symptoms are poorly controlled with inhaled corticosteroids, plus in Europe patients should also be receiving inhaled long-acting $\beta 2$ agonist bronchodilators.

In Europe, the licence also includes children aged 6 to $<12$ years as an add-on treatment for poorly controlled asthma in patients with severe persistent allergic asthma.

\section{Limitations}

- Small no. of patients were included in this study.

- Because of high cost of the drug study could not be conducted in a large scale

\section{Contribution by authors}

1) Dr. Saswata Gayen and Dr. Prosenjit Gayen: Concept designed and conducting the study.

2) Dr. Animesh Mandal: Conducting study and writing manuscript.

3) Prof. Ramtanu Bandyopadhyay: Guiding the study procedure and preparing the manuscript suitable for publication.

\section{Reference}

01. Humbert M, Beasley R, Ayres J, et al. Benefits of omalizumab as add-on therapy in patients with severe persistent asthma who are inadequately controlled despite best available therapy (GINA 2002 step 4 treatment)- INNOVATE. Allergy. 2005 Mar;60(3)309-16.

DOI: $10.1111 /$ j.1398-9995.2004.00772.x [Crossref] 
02. Curtis JR, Westfall AO, Allison J, et al. Population-based assessment of adverse events associated with long-term glucocorticoid use. Arthritis Rheum. 2006 Jun 15;55(3)420-6.

DOI: $10.1002 /$ art.21984 [Crossref]

03. Hanania NA, Alpan O, Hamilos DL, et al. Omalizumab in severe allergic asthma inadequately controlled with standard therapy- a randomized trial. Ann Intern Med. 2011 May 3;154(9)573-82.

doi: $\quad 10.7326 / 0003-4819-154-9-201105030-00002$ [Crossref]

04. Normansell R, Walker S, Milan SJ, et al. Omalizumab for asthma in adults and children. Cochrane Database Syst Rev. 2014 Jan 13(1)CD003559.

doi: 10.1002/14651858.CD003559.pub4 [Crossref]

05. D'Amato G. Role of anti-IgE monoclonal antibody (omalizumab) in the treatment of bronchial asthma and allergic respiratory diseases. Eur J Pharmacol. 2006 Mar 8;533(13)302-7.

DOI: 10.1016/j.ejphar.2005.12.045 [Crossref]

06. Rodrigo GJ, et al. Systematic review on the use of omalizumab for the treatment of asthmatic children and adolescents. Paediatric Allergy and Immunol. 2015;26;551-6.

[Crossref]

07. Molimard M, Buhl R, Niven R, et al. Omalizumab reduces oral corticosteroid use in patients with severe allergic asthma- real-life data. Respir Med. 2010 Sep;104(9)1381-5.

doi: 10.1016/j.rmed.2010.06.001 [Crossref]

08. Walker S, Monteil M, Phelan K, Lasserson T, Walters E. Anti-IgE for chronic asthma in adults and children. Cochrane Database of Systematic Reviews. 2006;2;CD003559.

doi: 10.1002/14651858.CD003559.pub3 [Crossref]

09. Rodrigo GJ, Neffen $H$, Castro-Rodriguez JA. Efficacy and safety of subcutaneous omalizumab vs placebo as add-on therapy to corticosteroids for children and adults with asthma- a systematic review. Chest. 2011 Jan;139(1)2835.

doi: 10.1378/chest.10-1194. DOI: $10.1378 /$ chest.101194 [Crossref]
10. Lanier B, Bridges T, Kulus $M$, et al. Omalizumab for the treatment of exacerbations in children with inadequately controlled allergic (IgEmediated) asthma. J Allergy Clin Immunol. 2009 Dec;124(6)1210-6. doi: 10.1016/j.jaci.2009.09.021 [Crossref]

11. Ohta K, Miyamoto T, Amagasaki T, et al. Efficacy and safety of omalizumab in an Asian population with moderate-to-severe persistent asthma. Respirology. 2009 Nov;14(8)1156-65.

doi: 10.1111/j.1440-1843.2009.01633.x [Crossref]

12. Hanania NA, Alpan O, Hamilos DL, et al. Omalizumab in severe allergic asthma inadequately controlled with standard therapy- a randomized trial. Ann Intern Med. 2011 May 3; 154(9)573-82.

doi: $\quad 10.7326 / 0003-4819-154-9-201105030-00002$ [Crossref]

13. Bardelas J, Figliomeni M, Kianifard F, et al. A 26week, randomized, double-blind, placebocontrolled, multicenter study to evaluate the effect of omalizumab on asthma control in patients with persistent allergic asthma. J Asthma. 2012 Mar;49(2)144-52.

doi: 10.3109/02770903.2011.648296 [Crossref]

14. Busse WW, Morgan WJ, Gergen PJ, et al. Randomized trial of omalizumab (anti-IgE) for asthma in inner-city children. N Engl J Med. 2011 Mar 17;364(11)1005-15.

doi: 10.1056/NEJMoa1009705 [Crossref]

15. Molimard $M$, Le Gros V. Impact of patientrelated factors on asthma control. J Asthma. 2008 Mar;45(2)109-13.

doi: $10.1080 / 02770900701815727$ [Crossref]

16. Korn S, Thielen A, Seyfried S, et al. Omalizumab in patients with severe persistent allergic asthma in a real-life setting in Germany. Respir Med. 2009 Nov;103(11)1725-31.

doi: 10.1016/j.rmed.2009.05.002 [Crossref]

17. Brusselle G, Michils A, Louis R, et al. "Real-life" effectiveness of omalizumab in patients with severe persistent allergic asthma- The PERSIST study. Respir Med. 2009 Nov;103(11)1633-42.

doi: 10.1016/j.rmed.2009.06.014 [Crossref] 
18. Niven $R$, Chung $K F$, Panahloo $Z$, et al. Effectiveness of omalizumab in patients with inadequately controlled severe persistent allergic asthma- an open-label study. Respir Med. 2008 Oct; 102(10)1371-8.

doi: $\quad 10.1016 /$ j.rmed.2008.06.002 [Crossref]

19. Cazzola M, Camiciottoli G, Bonavia M, et al. Italian real-life experience of omalizumab. Respir Med. 2010 Oct; 104(10)1410-6.

doi: $\quad 10.1016 /$ j.rmed.2010.04.013 [Crossref]

20. Tzortzaki EG, Georgiou A, Kampas D, Lemessios M, Markatos M, Adamidi $T$, et al. Long-term omalizumab treatment in severe allergic asthma- The South- Eastern Mediterranean reallife experience. Pulm Pharmacol Therapeut. 2012;25(1)77-82.

[Crossref]
21. Rottem M. Omalizumab reduces corticosteroid use in patients with severe allergic asthmareal-life experience in Israel. J Asthma. 2012 Feb;49(1)78-82.

doi: $10.3109 / 02770903.2011 .637598$ [Crossref]

22. Vennera Mdel C, Pérez De Llano L, Bardagí S, et al. Omalizumab therapy in severe asthmaexperience from the Spanish registry-some new approaches. J Asthma. 2012 May;49(4):416-22. DOI: $10.3109 / 02770903.2012 .668255$ [Crossref]

23. Corren J, Casale TB, Lanier B, et al. Safety and tolerability of omalizumab. Clin Exp Allergy. 2009 Jun;39(6)788-97.

doi: $10.1111 /$ j.1365-2222.2009.03214.x [Crossref] 